\title{
Factors Influencing Women's Representation in Leadership Positions: In Case of Ensaro Woreda Public Service Sectors, Amhara Region, Ethiopia
}

\author{
Bizualem Lemma Ketema \\ Lecturer, Debre Markos University, College of Business and Economics, Department of Management \\ Kasaye Zeleke Ferede \\ Tax Education Officer, Federal Ministry of Revenue, Large Tax Payer Office
}

\begin{abstract}
The issue of women on management position is gaining attention globally. Governments signed major human right treaties including the most important women's conventions to improve women's participation in management positions. Even though the government's effort to provide equal opportunities for women and design nondiscriminatory policies, the existences of glass ceiling practices undermine their progress. The objective of the study was examining factors influencing women representation in leadership positions in Ensaro woreda public sectors. To achieve the objective of the study 203 representative samples have taken trough proportionate stratified sampling method. And a series of statistical analysis have done. Descriptive statistics were used to describe the existing situation of women's representation of leadership in the public sectors, whereas, inferential statistics were used to investigate the association of women's representation with the set of predictor variables. Binary logistic regression result shows that cultural belief and attitude, insufficient capacity building, lack of professional training, inflexible working hours, inadequate experience, family commitments, inadequate job knowledge, inadequate academic qualification, lack of motivation and interests, limited access of advanced education and overall organizational culture have a significant effect on the under representation of women's leadership in public sectors. The study finding revealed that organizational and personal factors seem to have major contributors as compared to societal factors that hindered women representation in leadership position in public sectors. Finally, it is recommended that; awareness creation and counselling service should have given about gender equality, public sectors should be committed to encouraging women's to have a leadership positions, capacity building and special training should be given for women to increase the number of women leaders.
\end{abstract}

Keywords: Participation of women in leadership, societal factor, organizational factor, personal factor, Ensaro woreda public sectors.

DOI: $10.7176 / \mathrm{JCSD} / 60-02$

Publication date:June $30^{\text {th }} 2020$

\section{Introduction}

In principle, public administration is guided by principles of fairness, accountability, justice, equality and nondiscrimination, and serves as a model of governance for society which includes the promotion of gender equality and women's empowerment in the civil service workforce. However, globally; this is not yet the reality. Instead of being a driving force behind the implementation of internationally-agreed goals on gender equality and human rights standards and principles, in many developed and developing countries, public administration often remains a patriarchal institution, perpetuating gender biased traditions, attitudes and practices women do not yet participate equally in public administration, especially in leadership and decision-making (UNDP, 2014).

The United Nations development program report 2014 further stated that the target of a minimum of 30 percent of women in leadership positions, originally endorsed by the United Nations Economic and Social Council (ECOSOC) in 1990 and reaffirmed in the Beijing Platform for Action in 1995, is being approached in many public administrations and even surpassed in some. Nevertheless, while progress is being made in terms of total numbers of women in public administration, both glass ceilings and glass walls continue to present challenges to women's equal participation in decision-making positions (UNDP, 2014).

The Ethiopian Government has ratified the Convention on the Political Rights of Women (CPRW) and the Convention on Elimination of All Forms of Discrimination against Women (CEDAW). Ethiopia also adopted the principles of the 1995 Beijing Platform for Action (BPA) long before it adopted the Millennium Development Goals by 2000. Since issuing the National Policy on Women, Ethiopia has also put in place institutions aimed specifically at ensuring that the rights of women are respected, protected and fulfilled. Examples are Proclamations 471/2005 and 691/2010 that established Ministry of Women's Affairs (MOWA) and Ministry of Women, Children and Youth (MOWCYA), respectively (UNFPA, 2008).

Likewise, the Federal Democratic Ethiopia government committed to increase the participation of women in power and decision making. The national development plan (GTP) in 2010/11, has set the target of 30\% women's 
representation in education \& training for women higher leadership positions and $50 \%$ in medium leadership positions in the civil service by 2015; (Federal Democratic Republic of Ethiopia(FDRE) Report, 2015).

Despite the government's efforts to provide equal opportunities for women and design non-discriminatory policies, the existences of deep-seated discriminatory practices thwarted their progress, yet Ethiopian women are economically, socially, culturally and politically disadvantaged in the enjoyment of equal rights, in accessing opportunities, decision making processes, and basic resources. In other words, although a number of policies are emerging that support and encourage women's participation in development, women's access to and control of productive resources, information, training and education, employment and in decision-making are limited (Ogato, 2013).

In Ethiopia, as several of the empirical studies illustrate, such as (Endale, 2014;Yasin 2013; and Gelashe 2015;) the main barriers hindering women from public leadership and decision-making positions include Sociocultural attitudes, lack of assertiveness and lack of acquisition of the necessary experience for taking part in public decision-making, Over burden of domestic responsibilities continuation of the negative attitudes regarding women's ability to lead and govern, lack of role models of women leaders for young women and girls, and the like can be stated.

In the case of the study area Ensaro District Amhara regional Civil service women's representation \& participation in the local political activities and decision making roles are very low (Ensaro District public service, Report,2017). According to the report, almost all 26 public sectors permanent Employees, almost all are dominated by male leaders/ managers. Due to this reason, the permanent Employed women are still limited in subordinate's positions.

Despite the fact that there is progress being made in terms of total numbers of employed women in the woreda, segregation of women in management positions or disparity between men and women in terms of woreda decision making positions continue to exist which resulted in challenges to women to equal participation in decision-making positions. Women are also still underrepresented in local Government political position (Woreda Report, 2017). Therefore, underrepresentation and poor political participation has a global problem. Hence, this research examined the factors that affect women to participate in leadership/ management position in case of Public sector employees in Ensaro District, North Shoa Zone, and Amhara region.

\section{Statement of the Problem/Rationale}

In today's world, more women than ever are entering the labour force, but the majority of top management positions in almost all countries are primarily held by men managers generally women tend to be concentrated in lower management positions and have less authority than men. And in the same time women are still concentrated in traditionally "female" functional areas of companies such as; human resources, corporate communications, community and governmental relations marketing and finance (Akpinar-Sposito, 2012).

Despite efforts made to ensure that female representation is achieved at all levels of governance, due to patriarchal; stereotyping; organizational structure system African women are still underrepresented in many governments and nongovernment organizations particularly in positions of power and leadership (Kimba, 2008). The Africa Gender equality index also measured gender equality across three separate dimensions equality in economic opportunities, equality in human development, and equality in law and institutions. According to this study among 52 African countries Ethiopian overall ranks was $31^{\text {th }}$ by $(51 \%)$ it is too far from the first country ranks (74.5\%) which is South Africa (AFDB Report, 2015).

In the study area the gender imbalance or disparity of women in leadership /management position is becoming worst. For instance, according to Ensaro Woreda North Shoa Zone Amhara Region Civil Service annual report 2016/17 there were 430 men and women employees working in the 26 public sectors office. Out of the total permanent employees, 46 of them have political position and among 46 political leaders, only 9 or $(19.6 \%)$ were females. Among 92 processes owner and others different management position only 12 or (13\%) were females showing a very low coverage. In general, from the total 138 political and process owner positions, only 21 or (15.2\%) were taken by females (woreda public service Report, 2017).

Therefore, this study attempted to examine the existing gap and the factors influencing participation of women in leadership/ management position in the case of Ensaro Woreda public sectors.

\section{Objectives}

The general objective of the study is to examine factors influencing the representation of women in leadership positions in the Ensaro Woreda Amhara region public sectors. Specific objectives of the study includes: to assess the existing situation of women's representation in leadership positions in Ensaro Woreda public sectors; to determine the societal, organizational and personal factors that influence on Women's representation in leadership positions in public sectors. 


\section{Research Methods}

For the purpose of this study both descriptive and inferential research designs have been used. Descriptive statistics were used to assess the existing situation of women's representation in leadership positions in public sectors, whereas inferential statistics was used to examine the association between women's representation in leadership and the set of predictor variables. The target population were Civil servants who have been working in Ensaro Woreda North Shoa Zone Amhara Region. There are 430 Civil servants who have been working in the woreda. All the 430 respondents have been working at Woreda level and those have different educational status and managerial positions were proportionally included in the study.

In order to select the relevant sample probability sampling design was used. Samples were selected from each sector by using the proportionate stratified sampling technique.

The sample size calculated using Taro Yamane's (1973) formula $\mathrm{S}=\mathrm{N} /\left(1+\mathrm{Ne}^{2}\right)$ from the given 430 population by taking into accounts $0.05(5 \%)$ standard error or significant level.

Where, $\mathrm{S}=$ sample size

$\mathrm{N}=$ total number of male and females working at that public sectors

$\mathrm{e}=$ significance level or error

Using the above formula 203 representative samples were selected.

\subsection{Reliability and Validity Test}

In order to improve their validity and reliability of research instruments, a pilot test was done. According to Cronbach's, 1951 as cited by Alem Shumi (2007) Cronbach's it is a common miss conception that is Alpha is low; it must be a bad test. This is because the test may measure several attribution/dimensions rather than one and thus the Cronbach's Alpha is deflated. By Convention, lenient cut off 0.60 is common in explanatory study and some research require a cut of 0.80 for a good scale as a general rule of thumb (Shoukri and Edge, 1996), a reliability coefficient Alpha is excellent if Alpha is greater than 0.75; better if Alpha is between 0.40 and 0.74 and poor if Alpha is less than 0.40. Thus, the study Cronbach's Alpha test result showed (Table4.2).

Table 4.2 Reliability and validity test table

\begin{tabular}{|l|l|l|l|l|l|}
\hline NO & Factors name & Description & $\begin{array}{l}\text { No of } \\
\text { items }\end{array}$ & $\begin{array}{l}\text { No. } \\
\text { respondents }\end{array}$ & $\begin{array}{l}\text { Cronbach's } \\
\text { Alpha test }\end{array}$ \\
\hline 1 & Societal factors & $\begin{array}{l}\text { Explanatory } \\
\text { variable }\end{array}$ & 8 & 29 & 89.8 \\
\hline 2 & Organizational factors & $\begin{array}{l}\text { Explanatory } \\
\text { variable }\end{array}$ & 11 & 29 & 88.8 \\
\hline 3 & Personal factors & $\begin{array}{l}\text { Explanatory } \\
\text { variable }\end{array}$ & 7 & 29 & 85.1 \\
\hline 4 & $\begin{array}{l}\text { Women representation in } \\
\text { leadership position }\end{array}$ & $\begin{array}{l}\text { Outcome } \\
\text { variable }\end{array}$ & 8 & 29 & 76 \\
\hline
\end{tabular}

\section{Methods of Statistical Analysis}

\subsection{Logistic Regression}

Logistic regression analysis extends the techniques of multiple regression analysis to research situations in which the outcome variable is categorical. Logistic regression allows one to predict a discrete outcome, such as group membership, from a set of predictor variables that may be continuous, discrete, dichotomous, or a mix of any of these. Generally, the dependent or response variable is dichotomous (binary), such as presence or absence / success or failure/. Logistic regression has a peculiar property of easiness to estimate logit differences for data collected both retrospectively and prospectively (Mc Cullagh and Nelder, 1983). There are two main uses of logistic regression: primarily, it uses to predict the group membership. Since logistic regression calculates the probability of success over the probability of failure, the results of the analysis are in the form of an odds ratio (explanatory variable individual exposure). It also provides knowledge of the relationships and strengths among the variables.

\subsection{Logistic Regression Model Description}

The basic aim of modelling is to derive a mathematical representation of the relationship between an observed response variable and a number of explanatory variables, together with a measure of the inherent uncertainty of any such relationship. Statistical models constructed for response variables are the best an approximation to the manner in which an observable variable depends on other variables. No statistical model can be claimed to represent truth and, by the same token, no one model can be termed the correct model. Some models will be more appropriate than others, but typically, for any set of data, there will be a number of models, which are equally well suited to the purpose in hand, and the basis for choosing a single model from amongst them will not rest on statistical grounds alone. Statistical models are essentially descriptive and, in as much as they are based on experimental or observational data, may be described as empirical data (Collet, 1991). 
The dependent variable in logistic regression is usually dichotomous, that is, the dependent variable can take the value 1 with a probability of success $P_{i}$, or the value 0 with a probability of failure $1-P_{i}$. This type of variable is called a Bernoulli (or binary) variable.

Logistic regression makes no assumption about the distribution of the independent variables. They do not have to be normally distributed, linearly related or have equal variance within each group. The model for logistic regression analysis assumes that the outcome variable $\mathrm{Y}$ is categorical. When we assume that $\mathrm{Y}$ is dichotomous, taking on values of 1 (that is, positive outcome, or success) and 0 (that is, negative outcome, or failure). Then the conditional probability that the women are not participate on leadership given the $\mathrm{X}$ set of predictor variables is denoted by Probability $\left(Y_{i}=1 \mid X\right)=P_{i}$. The expression $P_{i}$ has the form:

$$
P_{i}=\frac{e^{\left(\beta_{0}+\beta_{1} x_{1 i}+\beta_{2} x_{2 i}+\cdots+\beta_{r} x_{r i}\right)}}{1+e^{\left(\beta_{0}+\beta_{1} x_{1 i}+\beta_{2 i}+\cdots+\beta_{r} x_{r i}\right)}}=\frac{e^{X^{\prime} \beta}}{1+e^{X^{\prime} \beta} \cdots \cdots \cdots \cdots \cdots \cdots}
$$

$\mathrm{P}_{\mathrm{i}}=$ the probability of women are not participate in leadership

$\mathrm{Y}_{\mathrm{i}}=$ the observed participation status of women in leadership

$\mathrm{B}=\mathrm{is}$ a vector of unknown coefficients.

The above model is logistic regression, in which the relationship between the predictor and response variables is not a linear function in logistic regression; instead, the logarithmic transformation of equation yields the linear relationship between the predictor and response variables. The logit transformation of $\mathrm{P}_{\mathrm{i}}$ given as follows:

$$
\operatorname{logit}\left[\mathrm{P}_{\mathrm{i}}\right]=\log \left(\frac{\mathrm{P}_{\mathrm{i}}}{1-\mathrm{P}_{\mathrm{i}}}\right)=\beta_{0}+\beta_{1} \mathrm{x}_{1}+\beta_{2} \mathrm{x}_{2}+\cdots+\beta_{\mathrm{r}} \mathrm{x}_{\mathrm{r}} \ldots \ldots \ldots \ldots \ldots \ldots \ldots
$$

\subsection{Fitting Logistic Regression Model}

The general method of estimation that leads to the least squares function under the linear regression model (when the error terms are normally distributed) is called maximum likelihood. It is this method that provides the foundation for our approach to estimation with the logistic regression model. In a very general sense the method of maximum likelihood yields values for the unknown parameters which maximize the probability of obtaining the observed set of data. In order to apply this, it is must to construct a function called likelihood function. The maximum likelihood estimators of these parameters are chosen to be those values which maximize this function. Thus, the resulting estimators are those which agree most closely with the observed data.

The maximum likelihood and non-iterative weighted least squares are the two most computing estimation methods used in fitting logistic regression model (Hosmer Lemeshow, 1989; Greene, 1991; Collet, 1991). When the assumption of normality of the predictors does not hold, the non- iterative weighted least squares method is less efficient (Maddala, 1997).

In contrast, the maximum likelihood estimation method is appropriate for estimating the logistic model parameters due to this less restrictive nature of the underlying assumptions (Hosmer Lemeshow, 1989). Hence, in this study the maximum likelihood estimation technique was applied to estimate parameters of the model. Consider the logistic model $P_{i}=\frac{e^{x^{\prime} \beta}}{1+e^{x^{\prime} \beta}}$, since observed values of $Y$ say, $y_{i}$ 's $(i=1,2,3 \ldots, n)$ are independently distributed as binomial with parameter $\mathrm{P}_{\mathrm{i}}$, the maximum likelihood function of $\mathrm{Y}$ is given by:

$$
\mathrm{L}(\beta \mid \mathrm{Y})=\prod_{\mathrm{i}=1}^{\mathrm{n}} \mathrm{P}\left(\mathrm{y}_{\mathrm{i}} \mid \mathrm{X}_{\mathrm{i} 1}, \mathrm{X}_{\mathrm{i} 2}, \ldots, \mathrm{X}_{\mathrm{im}}\right)=\prod_{\mathrm{i}=1}^{\mathrm{n}}\left[\frac{\mathrm{e}^{\mathrm{X}^{\prime} \beta}}{1+\mathrm{e}^{\mathrm{X}^{\prime} \beta}}\right]^{\mathrm{y}_{\mathrm{i}}}\left[\frac{1}{1+\mathrm{e}^{\mathrm{X}^{\prime} \beta}}\right]^{\left(1-\mathrm{y}_{\mathrm{i}}\right)} \ldots \ldots \ldots \ldots . . .
$$

Where, $\beta^{\prime}=\left(\beta_{1}, \beta_{2},, \beta_{r}\right)$. The objective of stating likelihood function is to get an estimator $\hat{\beta}=\left(\hat{\beta}_{0}, \hat{\beta}, \ldots, \hat{\beta}_{r}\right)$ of $\beta$ which maximizes the likelihood function expressed in equation (3.4). Since the likelihood equations are non- linear in the parameters, the Newton-Raphson iterative maximum likelihood estimation method that expresses $\hat{\beta}$ at the $(\mathrm{u}+1)^{\text {th }}$ cycle of the iteration is expressed as $\hat{\beta}_{u+1}=\left(\mathrm{X}^{\prime} \hat{V}{ }_{u} \mathrm{X}\right)^{-1}$ $\mathrm{XR}_{\mathrm{u}}$, Where $\mathrm{u}=0,1,2,3$, ...and is a diagonal matrix with its diagonal elements $\mathrm{Xi}=1$ ), $\hat{V}=\operatorname{diag}[p i(\hat{1-p i)}]=\operatorname{cov}(y)$. Finally, $\hat{\beta}$ is the resultant maximum likelihood estimator of $\beta$ with $\wedge$ residual $\mathrm{R}=\mathrm{y}-\hat{p}$ (Collet, 1991: Greene, 1991). Newton's method usually converges to the maximum of the log - likelihood in just a few iteration unless the data are especially badly conditioned (Greene, 1991). All the 
parameters $\hat{\beta}_{o}, \hat{\beta}_{1}, \ldots, \hat{\beta}_{r}$ and estimates of Probability $\left(\mathrm{y}_{\mathrm{i}}=1 / \mathrm{X}\right)$ for each subject was computed using the SPSS soft ware's.

\section{Results and Discussions}

\subsection{Descriptive Results}

6.1.1. General Demographics Comparison of Women and Men

Table 6.1 Bivariate Association between Women Representation in Leadership and Different Explanatory Variables

\begin{tabular}{|c|c|c|c|c|c|}
\hline \multirow[t]{2}{*}{ Variable } & \multirow[t]{2}{*}{ Category } & \multirow[t]{2}{*}{$\%$} & \multicolumn{2}{|c|}{ Respondents position } & \multirow{2}{*}{$\begin{array}{l}\text { Chi square } \\
\text { Pearson } \\
\text { correlation }\end{array}$} \\
\hline & & & leaders & Non leaders & \\
\hline \multirow[t]{2}{*}{ Sex } & Male & 52.8 & $103(83 . \% 1)$ & $0(0.0 \%)$ & \multirow[t]{2}{*}{$125(.000)$} \\
\hline & Female & 47.2 & $21(16.9 \%)$ & $71(77.2 \%)$ & \\
\hline \multirow{5}{*}{$\begin{array}{l}\text { Respondent } \\
\text { age }\end{array}$} & $18-25$ & 15.8 & $4(3.2 \%)$ & $27(38 \%)$ & \multirow[t]{5}{*}{$44.1(.000)$} \\
\hline & $26-35$ & 61 & $84(67.7 \%)$ & $35(49.3 \%)$ & \\
\hline & $36-45$ & 18.4 & $27(21.8 \%)$ & $9(12.7 \%)$ & \\
\hline & $46-55$ & 4.1 & $8(6.5 \%)$ & $0(0.0 \%)$ & \\
\hline & $\geq 56$ & 0.5 & $1(0.8 \%)$ & 0 & \\
\hline \multirow{3}{*}{$\begin{array}{l}\text { Respondent } \\
\text { marital status }\end{array}$} & Single & 56.9 & $83(66.9 \%)$ & $28(39.4 \%)$ & \multirow[t]{3}{*}{$16.3(.000)$} \\
\hline & Married & 42.1 & $41(33.1 \%)$ & $41(57.7 \%)$ & \\
\hline & Divorced & 1.0 & $0(0.0 \%)$ & $2(2.8 \%)$ & \\
\hline \multirow{4}{*}{$\begin{array}{l}\text { Number } \\
\text { children }\end{array}$} & 0 & 54.3 & $61(49 . \%)$ & $45(63.4 \%)$ & \multirow[t]{4}{*}{$33.99(.000)$} \\
\hline & $1-2$ & 42.1 & $58(46.8 \%)$ & $24(33.8 \%)$ & \\
\hline & $3-4$ & 2.5 & $3(2.4 \%)$ & $2(2.8 \%)$ & \\
\hline & $5-6$ & 1 & $2(1.6)$ & $0(0.0 \%)$ & \\
\hline \multirow{3}{*}{$\begin{array}{l}\text { Respondent } \\
\text { education }\end{array}$} & Certificate & 4.1 & $5(4.0 \%)$ & $3(4.2 \%)$ & \multirow[t]{3}{*}{$33.99(.000)$} \\
\hline & diploma & 47.6 & $40(32.3 \%)$ & $53(74.6 \%)$ & \\
\hline & $\begin{array}{l}\text { Bachelor } \\
\text { rdegree }\end{array}$ & 48.2 & $79(63.7 \%)$ & $15(21.1 \%)$ & \\
\hline \multirow{6}{*}{$\begin{array}{l}\text { Respondents } \\
\text { experience }\end{array}$} & $<3$ & 19.4 & $10(8.1 \%)$ & $28(39.4 \%)$ & \multirow[t]{6}{*}{$53.23(.000)$} \\
\hline & $3-5$ & 16.9 & $12(9.7 \%)$ & $21(29.6 \%)$ & \\
\hline & $6-10$ & 28.7 & $45(36.3 \%)$ & $11(15.5 \% 0$ & \\
\hline & $11-15$ & 25.6 & $41(33.1 \%)$ & $9(12.7 \%)$ & \\
\hline & $16-20$ & 1.5 & $2(1.6 \%)$ & $1(1.4 \%)$ & \\
\hline & $\geq 21$ & 7.6 & $14(11.3 \%)$ & $1(1.4 \%)$ & \\
\hline
\end{tabular}

Source: Own Survey Data, 2019

The descriptive statistics on all demographic variables reveal some differences between women and men. However, the final logistic regression result showed that (Table 6.1). Not all demographic back ground results are statistically significant effect. While the gender difference in terms of respondent's age, number of children and marital status not significant. In this study differed on education qualification and working experience as well as respondent's positions are found to be statistically significant.

According to the demographic background descriptive result the majority of women and men respondents (61\%), who participated in the study, are aged between 26 and 35 years Respondents with age below 25 and above 45 years are relatively low. With regard to respondents marital status $56.9 \%$ of the respondents are single $42.1 \%$ of respondents are married and about $1 \%$ of the respondents are divorced. Most of the respondents $(54.3 \%)$ do not have children. While, $82(42.1 \%)$ of respondents have $1-2$ children the rest $7(3.6 \%)$ respondents have $3-6$ children.

In terms of education the majority of male and female respondents $94(48.2 \%)$ of them have a bachelor's degree while $93(47.6 \%)$ of respondents have diploma and the rest $8(4.1 \%)$ respondents have certificate. In terms of women academic qualification out of a total 92 women $(31.5 \%)$ of them have bachelor's degree from the total of 21 leaders $14(66.6 \%)$ have a bachelor's degree $6(28.6 \%)$ of them have diploma the rest $1(4.7 \%)$ woman leader have a certificate. In general out of 92 women leaders, and non-leaders civil servants 29 (31.5\%) have bachelor's degree $59(30.7 \%)$ of them have diploma and the rest $4(4.3 \%)$ women's have a certificate. Regarding men respondents education qualification among 103 men leaders $65(63.1 \%)$ have bachelor's degree $34(33 \%)$ of them have diploma and the rest $4(4.3 \%)$ have certificate. In terms of male and female respondents' educational achievement comparison more men $(63.1 \%)$ have achieved than women $(31.5 \%)$ hold bachelor degree. According to the respondents educational background ground men have well developed academic background compare to 
women.

In terms of respondents work experience the majority of men and women respondents $106(54.3 \%)$ have 615 years of experience $18(9.2 \%)$ have between 6-21 years of experience $33(16.9 \%)$ have 3-5 years of experience and the rest $38(19.5 \%)$ of them have less than three years of experience. Regarding respondent experience Out of 21 women leaders $18(85.7 \%)$ have 6-21 working experience and the rest $3(14.2 \%)$ have less than 3 years of experience. Out of 71 non leaders women only $21(29.5 \%)$ have $6-21$ years of service and the majority of nonleaders women $50(70.4 \%)$ have under six years of service. From the total of 92 leaders and non-leaders women only $39(42.3 \%)$ have $6-21$ years of service and the rest $53(57.6 \%)$ have less than six years of service. Whereas, from the total 103 men leaders respondents $84(81.5 \%)$ have 6-21 working experience and the rest $19(18.4 \% \%$ have under 6 years working experience. As indicated in the table, respondents working experience demographic background data the majority of female and male leaders gained their leadership status after 6 years working experience and above.

In terms of female and male respondents work experience comparison data more men $84(81.5 \%)$ than women $39(42.3 \%)$ respondents have between 6-21 years of service. Therefore, the work experience demographic statistical data reveal that working experience in public sectors may have significant value to attain a political position and low level management position in public sectors.

\subsubsection{Association between Outcome Variable and Explanatory Variables}

Table 6.2 Pearson Correlation

\begin{tabular}{|l|l|r|r|}
\hline No & Description of Variables & value & Pearson correlation \\
\hline 1 & Cultural beliefs and attitudes towards women role and leaders ability & 19.21 & .000 \\
\hline 2 & Gender stereo type & 10.47 & .001 \\
\hline 3 & Mother hood & 16.68 & .000 \\
\hline 4 & Lack of support from family & 8.06 & .005 \\
\hline 5 & patriarchal attitude (ideology) & 8.5 & .004 \\
\hline 6 & fewer opportunities for women education & 16.57 & .000 \\
\hline 7 & house hold responsibilities & 57.12 & .000 \\
\hline 8 & Conflicts between personal and work life & 9.39 & .002 \\
\hline 9 & Over all public sectors internal culture & 89.94 & .000 \\
\hline 10 & Government recruitment and selection practices & 17.2 & .000 \\
\hline 11 & Government Promotion practices & 10.12 & .001 \\
\hline 12 & Limited accesses to advanced education for women & 19.79 & .000 \\
\hline 13 & Limited accesses to professional training for women & 12.22 & .000 \\
\hline 14 & In sufficient leadership capacity building for women & 47.5 & .000 \\
\hline 15 & Absence of formal mentoring and women networking programs & 6.59 & 0.37 \\
\hline 16 & The difficulty of balancing works and personal lives & 47.62 & .000 \\
\hline 17 & The existence of Few numbers of female leaders in public sectors & .727 & .394 \\
\hline 18 & Lack of support from supervisors & 7.85 & .005 \\
\hline 19 & Un attractive working environment & 9.62 & .001 \\
\hline 20 & Inflexible working hours influence & 23.49 & .000 \\
\hline 21 & Lack of confidence, among women & 39.6 & .000 \\
\hline 22 & Lack of family commitments & 8.31 & .004 \\
\hline 23 & Women's marital status & 9.12 & .003 \\
\hline 24 & Women have been lack of motivation and interests & 9.79 & .002 \\
\hline 25 & In adequate job knowledge (capability) & 12.93 & .000 \\
\hline 26 & In adequate academic qualification & 12.49 & .000 \\
\hline 27 & In adequate professional (working) experience & 79.36 & .002 \\
\hline 28 & Differences in leadership styles of women & 88.5 & .004 \\
\hline
\end{tabular}

Source: Own Survey Data, 2019

Model-building strategies begin with a careful descriptive analysis of each variable. The preliminary analysis has been done to understand which of the explanatory variables appears to have a strong association with response variable. For each one of the independent variables, a test of association was carried out using the Pearson ChiSquare at 5\% level of significance. High values of Pearson chi-square for a given independent variable indicate that there is a strong association between each of the given independent variables and response variables keeping the effect of the other factors constant. The bivariate association of societal, organizational and personal factors with that of representation of women in leadership shows that there is a strong correlation which is indicated by Pearson correlation (Table 6.2). 
Table 6.3: Parameter Estimates, Variables Standard Error and Odds Ratio for the Final Logistic Regression of Participation of Women and other predictors

\begin{tabular}{|c|c|c|c|c|c|c|c|c|}
\hline No & Description of Variables & categories & B & S.E. & Wald & $\mathrm{df}$ & Sig. & $\begin{array}{l}\operatorname{Exp}(B) \text { or } \\
\text { Odds Ratio at } \\
95 \% \text { C.I }\end{array}$ \\
\hline \multirow[t]{2}{*}{1} & \multirow[t]{2}{*}{ Cultural belief and attitude } & Negative & 1.59 & .680 & 5.472 & 1 & .019 & 4.910 \\
\hline & & Positive (ref) & & & & & & \\
\hline \multirow[t]{2}{*}{2} & \multirow{2}{*}{$\begin{array}{l}\text { Insufficient capacity } \\
\text { building }\end{array}$} & Yes & 2.70 & .723 & 14.005 & 1 & .000 & 14.939 \\
\hline & & No (ref) & & & & & & \\
\hline \multirow[t]{2}{*}{3} & \multirow{2}{*}{$\begin{array}{l}\text { Lack of professional } \\
\text { training }\end{array}$} & Yes & 1.95 & .706 & 7.694 & 1 & .006 & 7.096 \\
\hline & & No (ref) & & & & & & \\
\hline \multirow[t]{2}{*}{4} & \multirow[t]{2}{*}{ Inflexible working hours } & Yes & 2.65 & .716 & 13.743 & 1 & .000 & 14.209 \\
\hline & & No (ref) & & & & & & \\
\hline \multirow[t]{2}{*}{5} & \multirow[t]{2}{*}{ In adequate experience } & Yes & 2.56 & .696 & 13.625 & 1 & .000 & 13.047 \\
\hline & & No (ref) & & & & & & \\
\hline \multirow[t]{2}{*}{6} & \multirow[t]{2}{*}{ Family commitments } & Yes & -1.23 & .658 & 3.534 & 1 & .060 & .290 \\
\hline & & No (ref) & & & & & & \\
\hline \multirow[t]{2}{*}{7} & \multirow[t]{2}{*}{ In adequate job knowledge } & Yes & 1.261 & .627 & 4.049 & 1 & .044 & 3.530 \\
\hline & & No (ref) & & & & & & \\
\hline \multirow[t]{2}{*}{8} & \multirow{2}{*}{$\begin{array}{l}\text { Inadequate academic } \\
\text { qualification }\end{array}$} & Yes & 1.594 & .668 & 5.698 & 1 & .017 & 4.925 \\
\hline & & No (ref) & & & & & & \\
\hline \multirow[t]{2}{*}{9} & \multirow{2}{*}{$\begin{array}{l}\text { Lack of motivation And } \\
\text { interests }\end{array}$} & Yes & 1.753 & .706 & 6.169 & 1 & .013 & 5.774 \\
\hline & & No (ref) & & & & & & \\
\hline \multirow[t]{2}{*}{10} & \multirow{2}{*}{$\begin{array}{l}\text { Limited access of } \\
\text { advanced education }\end{array}$} & Yes & -1.616 & .660 & 6.001 & 1 & .014 & .199 \\
\hline & & No (ref) & & & & & & \\
\hline \multirow[t]{3}{*}{11} & \multirow{2}{*}{$\begin{array}{l}\text { Over all organisational } \\
\text { culture }\end{array}$} & Yes & -1.450 & .657 & 4.876 & 1 & .027 & .234 \\
\hline & & No(ref) & & & & & & \\
\hline & Constant & & -8.200 & 1.583 & 26.818 & 1 & .000 & .000 \\
\hline
\end{tabular}

Source: Own Survey Data, 2019

\subsection{Result and Discussion for Binary Logistic Regression Analysis}

The main problem with any univariate approach is that it ignores the possibility that a collection of variables, each of which is weakly associated with the outcome, can become an important predictor of the outcome when taken together (Hosmer and Lemeshow, 2000). Hence, multivariate logistic regression filters the nominated variables for the second time to differentiate variables with good potential that have a significant effect on the response variable.

From the total variables entered for multiple covariate logistic regression, about 11 of them pass the filtration of forward LR of logistic regression (Table 4.3). Namely, cultural belief and attitude, insufficient capacity building, lack of professional training, inflexible working hours, inadequate experience, family commitments, inadequate job knowledge, inadequate academic qualification, lack of motivation and interests, limited access to advanced education and overall organizational culture have a significant effect on the participation of women in leadership at the $5 \%$ level of significance.

Table 4.3 shows the multiple logistic regressions between the position of women and the other predictor variables. The table shows that cultural belief and attitude towards women is significantly affect the participation of women in leadership position. It shows that respondents who have negative cultural attitude towards women role and leadership are 4.91 times exposed for the non- managerial position than respondents with positive attitude. The insufficient Capacity building has also its own effect on the position of women in their public sectors the result indicates that women having insufficient capacity building are 14.94 times exposed to the subordinate position than women having sufficient capacity building. The odds of non- managerial position for women having less than three years of work experience is 13.05 times with that of women having more than three years of work experience. Women with an in adequate academic qualification are 4.93 times exposed to non- managerial position than that of women with adequate academic qualification. Lack of motivation and interests has also its own effect on the representation of women in leadership. The result below indicates that women with lack of motivation and interest to be manager are 5.77 times exposed for the non -managerial position than that of women having motivation and interest for the managerial position. The detailed result of other predictor variables is given in the (Table 4.3).

The result of the interviewees equally supports the above inferential results. The detailed questionnaires result listed as follows.

With regard to societal factors to support the questionnaire ten women leaders were targeted for interview 
out of 10 leaders $9(90 \%)$ of them were participating in the interview. To identify specific societal factors which contribute the underrepresentation of women in the woreda public sectors the interviewed respondents were asked similar semi structured interview questions about societal factors which are affected women in leadership positions in public sectors. The majority of interviewees' women leaders' regarding societal factors said:

“Indeed societal attitude and cultural beliefs towards women's leadership, not only leadership, but also regarding women's education in the Woreda context as we have seen the awareness of society significantly has improved for the last two and a half decade. Majority of study area society, belief and attitudes towards women's education and leadership has been changed. The society gradually understood the adverse effect of harmful traditional practice and for the equal enjoyment of rights by women's, where parents start to send their girls to school in all directions. However, the deep social, cultural practices and trends still played their own role for women's career advancements. Due to strict societal rules the majority of women still limited in house hold activities while men perform activities outside the home specially women in the woreda rural areas are heavily burdened in house hold activities. According to the interviewed suggestion women public servants specially have been faced another serious challenge after completing their higher education and hired in the public sectors which is long working hours in the office compounds, many women's due to lack of family support women mainly could not balance their home and work responsibilities". Thus, due to culturally prescribed roles of women still yet, women did not balance their household work and office work. Therefore, this may have adverse effect for women's career advancements in public sectors.

With regard to organizational factors to support the questionnaires and to identify the Woreda public sectors over all internal cultures particularly regarding in service training and women's leadership capacity building trends the Ensaro Woreda civil service office employee recruitment and selection process owner was interviewed and in this regard the process owner said:

"At the time of employee recruitment and selection, public sectors women's civil servant employees have given affirmative action and more treated differently than men still the Ethiopian civil service proclamation and policies more favoured women than men. However, due to the absence of targeted allocated budget still now there is no annual target plan to promote women to different management position in all Woreda public sectors to narrow the gender gap. Further, still now there is no allocated budget for women's employees in service training and leadership capacity building purpose to upgrade women to different leadership position." Thus, the absence of women leadership capacity building and on service training may have adverse effects for women's career advancements in public sectors.

With regard to personal factors to support the questionnaires and to examine the degree of personal factors that affects women leadership in public sectors the women leaders were also interviewed. And in this regard the majority of interviewed leaders said:

"Although at the country's level, Regional and Zonal, as well as Woreda level women have still faced negative cultural beliefs and attitudes towards women's leadership and unsupportive public sectors or internal culture continued as a barrier of women in leadership position. However, women themselves due to the absence of their own efforts, commitments, and the Woreda public sectors women acquire less education qualification and work experience comparable to men employees." Therefore, women did not fulfil the minimum requirement needed by public sectors to leadership position compared to men employees. According to interviewed respondent the Woreda women's civil servants due to lack of relevant qualification and work experience women still under represented in leadership positions in public sectors.

\section{Conclusions and Recommendations}

\subsection{CONCLUSIONS}

The descriptive result of this study shows that from the total sampled respondent only $11 \%$ of them are women having the managerial position others have non managerial/subordinate position. And about $59 \%$ of the respondents have the negative cultural attitude towards women's leadership in public sectors, so, that its effect has shown in the descriptive part of this study. From the inferential result, it is evident that cultural belief and attitude, insufficient capacity building, lack of professional training, inflexible working hours, inadequate experience, family commitments, inadequate job knowledge, inadequate academic qualification, lack of motivation and interests, limited access to advanced education and overall organizational culture have a significant effect on the under representation of women's leadership in public sectors.

Women having a lower educational level (diploma and below), less than three years of service, negative cultural attitude, negative organizational culture, insufficient capacity building, lack of professional training, lack of family commitments, inflexible working hours, less motivation and interest of women and limited access of advanced education leads or exposed women for non- managerial positions on their public sectors. Thus, it is concluded that women's career advancements in public sectors are not affected by one factor alone, but a combination of Societal, Organizational and Personal factors are the major factors to contribute under the representation of women in public sectors. However, According to Inferential statistics analysis result, 
organizational and personal factors seem to have major contributors as compared to societal factors that hindered women's representation in leadership positions in public sectors.

\subsection{Recommendations}

Based on the result of the study and the conclusion above the following recommendations have been forwarded to the Amhara Regional state and other concerned public sectors in the region:

- To minimize the gender disparity the Amhara Regional Government should have established minimum gender quota for women professional development, capacity building and in-service training at regional as well as zonal and woreda level.

- Deep cultural change such as, developing information campaigns and creating awareness programs about gender stereotypes, inequitable division of household /family care, conscious and un-conscious biases and the social and economic benefits of gender equality are the necessary measure to enhance women's leadership in public sectors.

- The woreda administration and woreda Public sectors should be committed to encouraging women to have a leadership position.

- In order to reduce the negative cultural and organizational impacts on female leaders, there should be a culture of encouraging women leaders at grassroots levels as in Woreda, Kebele and school settings of leadership by organizing monthly, quarterly and yearly events of star female leaders.

\section{REFERENCE}

A.M.Yasin (2013). UvA-DARE is a service provided by the library of the University of Amsterdam (http://dare.uva.nl). Retrieved Feburary Download date: 27 Jan 2017, from the Library: http://uba.uva.nl/en/contact, or a letter to: Library of the University of Amsterdam, Secretariat, Singel 425, 1012 WP Amsterdam.

AFDB,OECD,UNDP. (2016). aFRICAN Economic out look:sustainable cities and structural transformation. Abidjan Paris Newyork: African Economic out look.

Akpinar-Sposito, C. (2012). Career barriers for women executives and the glass ceiling syndrom: the case study comparation between French and Turkey. 2nd International Conference on Leadership (p. 11). Istanbul: halshs.

Endale, H. (2014). Factors that affect women participation in leadership and decision making position. Asian Journal of humanity, Art and literature, 113.

Endale, H. (2014). Factors that affect women participation in leadership and decision making positions. Asian journal of Humanity, 98.

M.kiamba, J. (2008). Women and leadership positions: cultural Barriers to success. Wagadu 2008 ISSN: 1545 $5196,8$.

M.Kimba, J. (2008). Women and leadershp positions :social and cultural barriers to success. Wagadu 2008 ISSN, $1545-6196$.

Ogato, G. (2013). the quest for gender equality and women's empowerement in least developed countries policy and strategy implications for achieving Millennium developments goal in Ethiopia. International journal of sociology, 359.

Shumiye, A. (2007, August). Determinants of food in security in rural house hold in Tehuiudere Woreda; South Wello Zone. Tehuludere, Tthuludere, Amhara: Unpublished.

Gelashe, J. (2015). Assessement of factors affecting women participation in managerial position. Global Journal of management and Business Research, -.

UNDP. (2014). Gender equality in public sector. New york: UNDP.

UNFPA. (2008). Gender inequality and women's empowerement Ethiopian society of population studies. UNFPA, 19-21. 